\title{
Sudanophil leucodystrophy in a pachygyric brain
}

\author{
R. M. NORMAN, A. H. Tingey, J. C. VAlentine, AND T. A. DANBY \\ From the Burden Neuropathological Laboratory, Frenchay Hospital, Bristol, the \\ Bedford General Hospital, and the Bromham Hospital, Bedford
}

Recent classifications of the diffuse cerebral scleroses have recognized the need to subdivide those cases which share in common the feature of sudanophil breakdown products of myelin. In Schilder's disease, as represented by the case he described in 1912, there are large, bilocular, sharply demarcated areas of demyelination in the centrum ovale, often associated with smaller plaques similar to those of multiple sclerosis. In contrast to this condition, there are cases in which the demyelination is much more diffuse and involves the gyral cores, the cerebellar white matter, and often parts of the brain-stem, while the degeneration products, as in Schilder's disease, are neutral fat and cholesterol esters. This group has been given a variety of names: 'neutral fat leucodystrophy' (Poser and van Bogaert, 1956), 'simple degenerative diffuse sclerosis' (Hallervorden, 1957), and 'sudanophil-orthochromatic leucoencephalopathy' (Einarson and Strömgren, 1961). We prefer the simple name 'sudanophil leucodystrophy' because there are other sudanophil substances present in addition to neutral fat. This generic term also includes in its scope the heterogeneous collection of cases at present classed as Pelizaeus-Merzbacher disease.

There is often a genetic background to these sudanophil leucodystrophies which is foreign to the Schilder type, but in sporadic cases it may sometimes be difficult to distinguish the two conditions by purely neuropathological criteria (Einarson and Strömgren, 1961). At the present time few cases of sudanophil leucodystrophy have been chemically analysed but there is some evidence pointing to differences between this group and cases of Schilder's disease. We have thought the present case worth recording not only because of the unusual combination of sudanophil leucodystrophy with a gross malformation of the cortex but because chemical analysis of the brain has shown certain features linking the condition to other types of inherited diseases of the white matter.

\section{CASE REPORT}

CLINICAL HISTORY G.P.W., a boy, was born on 29 September 1956 and died on 17 January 1959 aged
2 years 4 months. He was the second child of healthy parents. There is an elder sibling, a girl, now 8 years old, who is a microcephalic idiot with severe spastic paraplegia and closely resembles her brother in appearance and neurological state. She has nystagmus with squint and no optic atrophy or changes in the fundus. Her fingers are long and tapering, suggesting arachnodactyly. A second cousin who died in early childhood is said to have had a very small head.

The patient was admitted to a hospital for mental defectives at the age of 18 months. He was a microcephalic idiot with head circumference of 15 in. $(38 \mathrm{~cm}$.), large ears, receding chin, a creamy pallor of face, and a mass of red curls. Concomitant squint and nystagmus were noted. He suffered from spastic paraplegia and was difficult to feed owing to regurgitation of food. He habitually held his thumbs tightly in the palms of his hands. Death occurred unexpectedly after a sudden collapse.

NECROPSY FINDINGS The body was that of a thin but not wasted boy, apparently about 18 months of age. The head was small and somewhat elongated. The ears appeared extraordinarily large. The mouth contained natural teeth and the palate was high and arched. There was generalized pallor of the skin, the fingers of both hands were extremely long and tapering, and there was considerable oedema of the backs of the hands. Both feet were somewhat elongated and showed non-pitting oedema. The testes were not found in the scrotum.

The heart (27 g.) and blood vessels were normal. The lungs showed diffuse bronchopneumonia. The spleen (17 g.), bone marrow, and lymph nodes were normal in appearance. The liver $(535 \mathrm{~g}$.) was considerably enlarged and showed a uniform pale yellow colour with a fine, light brown reticulation. The intestinal tract, kidneys, ureters, bladder, suprarenals, and thyroid were normal. The skeletal muscles appeared normal when allowance was made for the fact that this patient had been all his life in bed.

The cranial sutures were all united and the dura mater was firmly adherent to the vault of the skull. There was no evidence of infection in the middle ears. The roof of the orbits bulged upwards into the cranial cavity but the bone was not thickened. There was a considerable excess of cerebrospinal fluid over the surface of the brain.

BACTERIOLOGY No virus was detected in the lung tissue. Specimens from the heart and lungs gave a mixed growth of staphylococci, pneumococci, and haemophilus. 
HISTOLOGY There was a diffuse bronchopneumonia. The majority of alveoli contained vacuolated cells containing sudanophil lipid which was not doubly refractile and did not reduce osmic acid. The spleen was congested. No abnormal phagocytes or lipid were seen. The liver showed gross fatty change. The majority of cells, with the exception of a few around the portal areas, showed the cytoplasm to be occupied by a single, large, clear vacuole. There was some polymorphonuclear infiltration of the portal areas. The pancreas was normal. The muscle cells of the heart muscle appeared normal. There was perhaps slight thickening of the endocardium. The kidneys were normal except for foamy degeneration of the cells of the proximal convoluted tubules.

\section{STUDY OF THE CENTRAL NERVOUS SYSTEM}

MACROSCOPIC After fixation in formol saline the brain weighed $353 \mathrm{~g}$., the cerebellum and brain-stem accounting for $57 \mathrm{~g}$. The cranial nerves and blood vessels were unremarkable. The convolutional pattern was grossly abnormal. The frontal lobes were smooth except for shallow sulci demarcating broad 'superior frontal' gyri and the gyri recti. In each hemisphere the frontal region was bordered posteriorly by a deep sulcus running downwards and forwards towards the anterior end of the Sylvian fissure (Fig. 1). In the parietal lobes shallow sulci ran in the same direction and no interparietal sulci

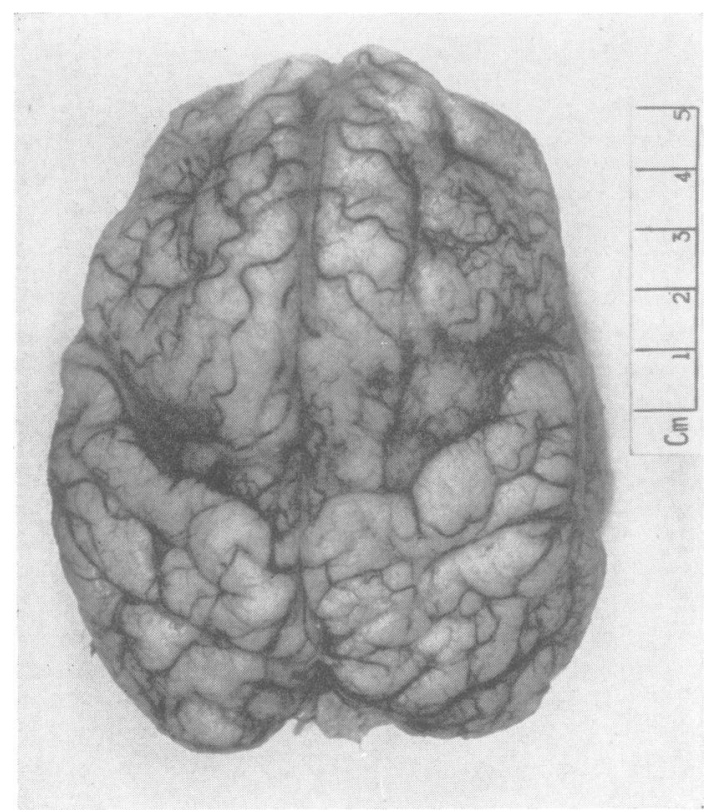

FIG. 1. Dorsal aspect of brain showing irregularity of convolutional pattern. were present. The occipital lobes were more normally convoluted, transverse occipital and calcarine fissures being identified. The temporal lobes were almost smooth on the convexity (Fig. 2). The hippocampal gyri were well developed. A thin corpus callosum was present. No malformation was seen in the cerebellum but there was obvious atrophic shrinkage of the lateral lobes.

MICROSCOPIC Representative regions of the cerebral hemispheres, basal ganglia, cerebellum, and brainstem were examined by frozen and celloidin sections stained for nerve cell bodies, axis cylinders, myelin, fibrous neuroglia, and lipid.

Changes in the white matter Large celloidin sections stained by Heidenhain's method revealed an almost complete absence of myelin in the centrum ovale and gyral cores, except for a feeble staining in parts of the cingulate and hippocampal gyri (Fig. 3). Similar changes were seen in frozen sections stained by Kultschitsky-Pal's method. The anterior part of the corpus callosum contained some well-stained but beaded fibres. Gros-Bielschowsky preparations showed that axis cylinders were well preserved in all these areas, though some fibres showed beading (Fig. 4). The Holzer stain revealed a slight diffuse fibrous gliosis which became denser beneath the calcarine cortex in the demyelinated occipital lobe. Closely packed microglial phagocytes filled with scarlet staining and doubly refractile lipids were uniformly dispersed throughout the whole white matter and showed little tendency to aggregate around blood vessels (Fig. 5). There was no metachromatic or P.A.S.-positive material in the tissues.

In the basal ganglia (Fig. 3) the thalami had retained their normal pattern of myelinated fibres

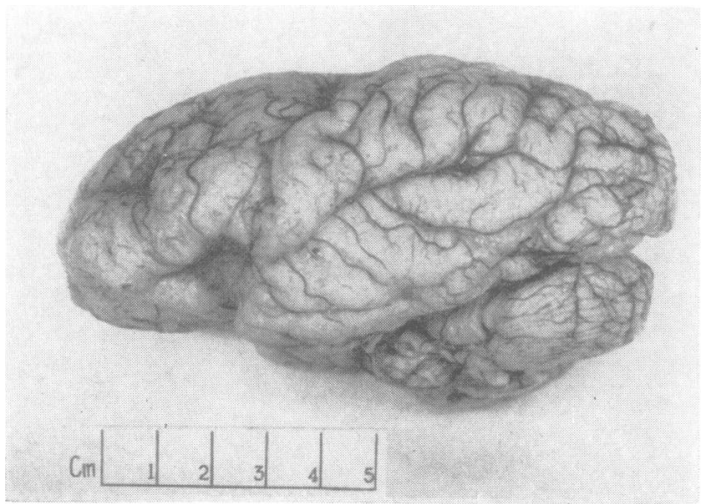

FIG. 2. Lateral aspect of left hemisphere showing agyric temporal lobe. 

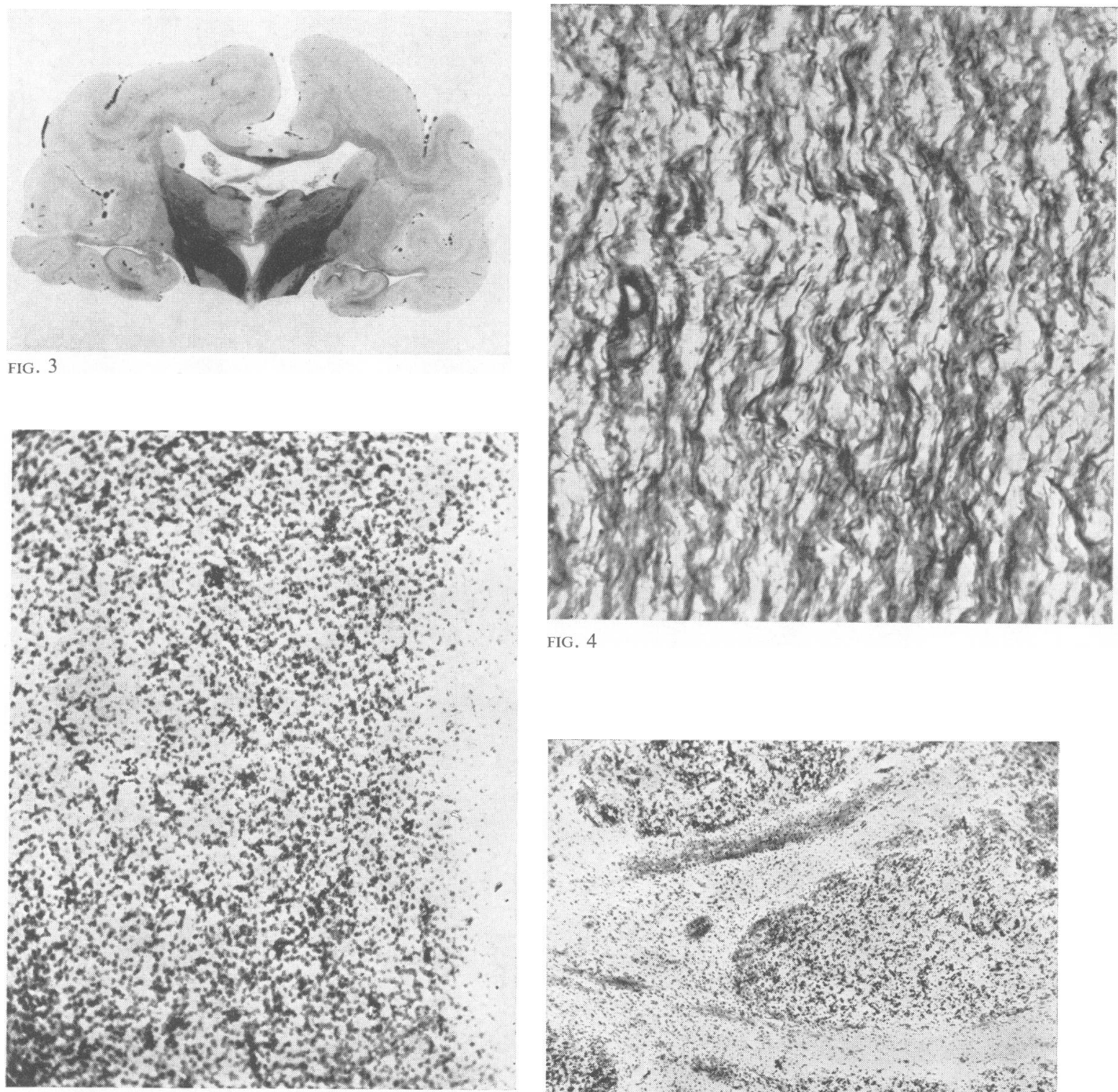

FIG. 5

FIG. 3. Coronal section showing poverty of myelin in the centrum ovale. Heidenhain $\times 1 \cdot 4$.

FIG. 4. Frontal white matter showing well preserved axis cylinders. Gros-Bielschowsky $\times 255$.

FIG. 5. Occipital white matter showing diffusely distributed fat granule cells. Scharlach $R$ and haematoxylin $\times 40$.

FIG. 6. Pons showing fat granule cells in the cortical projection tracts. Scharlach $R$ and haematoxylin $\times 60$.

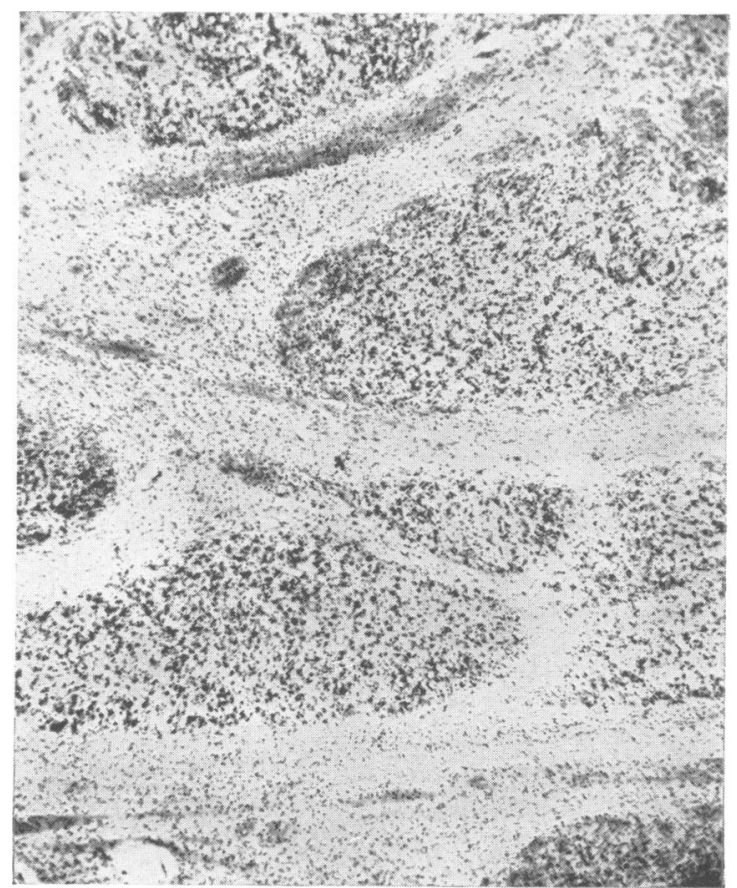

FIG. 6 
but these stained rather less intensely than normal. Only the subthalamic nuclei and tegmental radiations appeared fully myelinated. The fibre systems of the globus pallidus and putamen on each side were severely demyelinated and contained large numbers of fat granule cells. The internal capsule, optic tract, and anterior pillars of the fornix contained numerous palely staining, swollen fibres and were clearly marked out in fat preparations by the presence of closely packed sudanophil phagocytes.

Similar appearances were presented by the cortical projection systems in the crura, pons, and pyramids (Fig. 6), though in the cerebral peduncles an outer rim of well-myelinated fibres was present. Myelin sheaths were absent or scanty in the substantia nigra, the reticular formation of the medulla, and the hila of the inferior olives (Fig. 7). These areas contained few or no fat granule cells. Feeble staining rather than frank demyelination was a feature of the transverse fibres of the pons. The mesial fillet contained abundant fat granule cells only at pontine level. In the medulla the pyramids were of neonatal size and the inferior olives normally convoluted.

In all areas of severe or partial demyelination the axis cylinders were well preserved. Fibrous gliosis

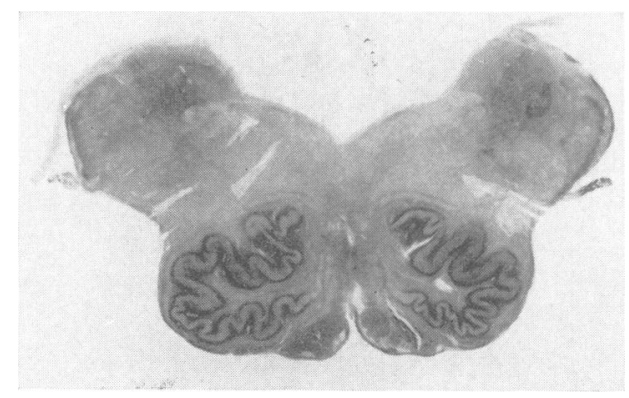

FIG. 7. Medulla showing general poor staining of the myelin and demyelination of the olivary hila, mesial fillet, and reticular formation. Kultschitsky-Pal $\times 3$.

was generally inconspicuous in the pes pontis, the mesial fillet at pontine level, and in the hila of the olives.

The cerebellar white matter in the vermis and lateral lobes was shrunken and showed an incomplete loss of myelin sheaths (Fig. 8), the individual fibres often appearing pale with irregular swellings. Rather better staining of fibres was seen peripherally in the gyral cores and in the granular layer. Gliosis was mild except in some of the medullary cores of the semilunar and quadrangular lobes. Axis cylinders

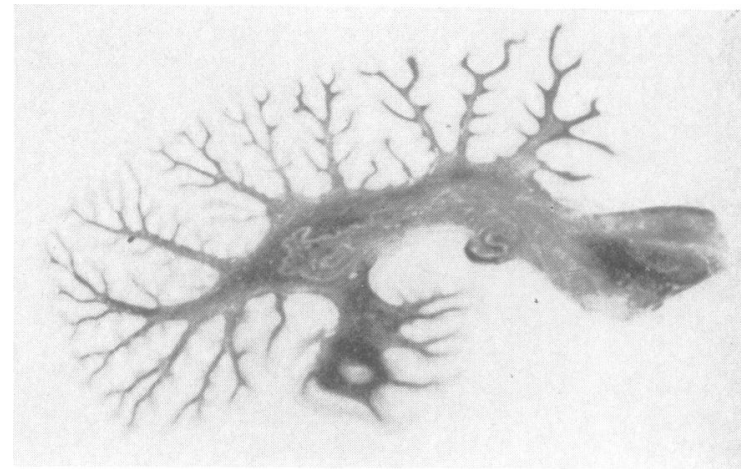

FIG. 8. Lateral lobe of cerebellum showing diffuse demyelination. Kultschitsky-Pal $\times 1.5$.

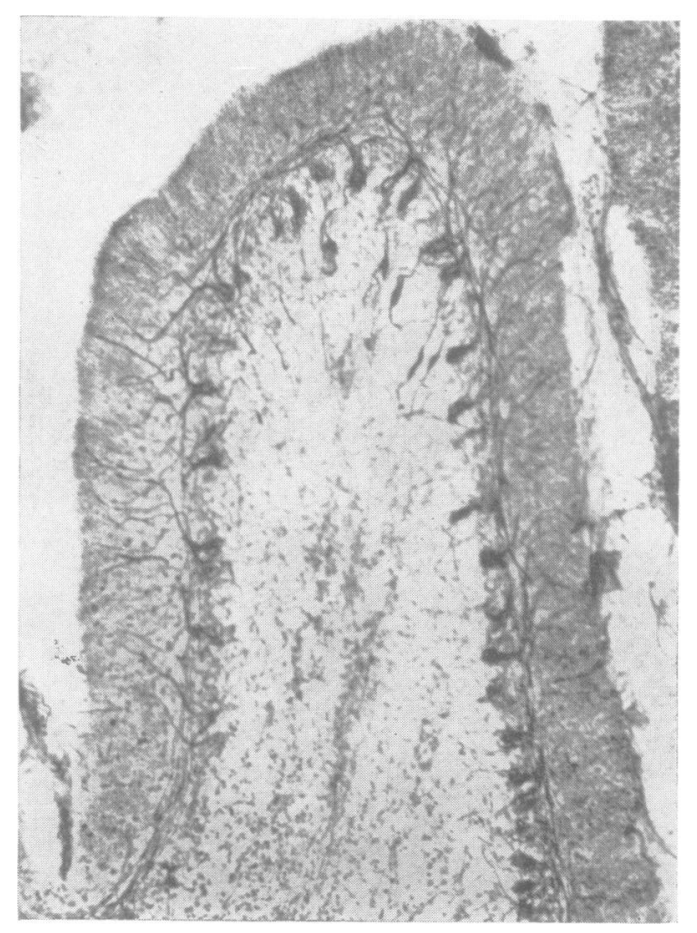

FIG. 9. Cerebellum showing atrophy of the granular layer and preservation of Purkinje cells. A few axonal torpedoes are seen. Cajal's silver nitrate-pyridine method $\times 105$. 
TABLE

RESULTS OF CHEMICAL ANALYSIS OF THE BRAIN IN GRAMS PER 100 GRAMS OF DRY TISSUE

\begin{tabular}{|c|c|c|c|c|c|c|}
\hline & \multicolumn{3}{|l|}{ White Matter } & \multicolumn{3}{|c|}{ Cerebral Cortex } \\
\hline & Case G.P.W. & Neonatal & Normal $2 \frac{1}{2}$ Years & Case G.P.W. & Neonatal & Normal $2 \frac{1}{2}$ Years \\
\hline Total lipid & $35 \cdot 6$ & $35 \cdot 9$ & $50 \cdot 7$ & $30 \cdot 0$ & $32 \cdot 8$ & $30 \cdot 3$ \\
\hline Total lipid hexose & 1.06 & 1.05 & 2.43 & 0.89 & $1 \cdot 15$ & 0.85 \\
\hline Neutral hexose & $0 \cdot 17$ & 0.36 & $1 \cdot 53$ & 0.20 & $0 \cdot 16$ & 0.29 \\
\hline Lipid hexosamine & $0 \cdot 116$ & 0.081 & 0.045 & 0.210 & 0.096 & 0.048 \\
\hline Neuraminic acid & 0.392 & 0.354 & $0 \cdot 130$ & 0.446 & $0 \cdot 352$ & 0.490 \\
\hline Lipid sulphur & 0.050 & 0.064 & $0 \cdot 116$ & $0 \cdot 147$ & 0.085 & $0.075^{1}$ \\
\hline Total hexosamine & 0.595 & 0.662 & 0.285 & 0.750 & 0.716 & $0.415^{1}$ \\
\hline Residue hexosamine & 0.479 & 0.581 & $0 \cdot 240$ & 0.540 & 0.687 & 0.196 \\
\hline Cholesterol free & $4 \cdot 0$ & $5 \cdot 3$ & $12 \cdot 6$ & $3 \cdot 0$ & $4 \cdot 3$ & $5 \cdot 3$ \\
\hline Cholesterol ester & 3.4 & 0.4 & nil & $0 \cdot 3$ & 0.02 & $0 \cdot 1$ \\
\hline Total phosphatide & $11 \cdot 0$ & $23 \cdot 4$ & $15 \cdot 4$ & $15 \cdot 2$ & $22 \cdot 0$ & $14 \cdot 7$ \\
\hline Lecithin & 6.7 & $10 \cdot 4$ & $7 \cdot 4$ & $7 \cdot 9$ & $10 \cdot 8$ & $8 \cdot 3$ \\
\hline Sphingomyelin & $2 \cdot 6$ & $0 \cdot 1$ & $2 \cdot 6$ & $1 \cdot 0$ & 0.3 & $1 \cdot 7$ \\
\hline Cephalin B & nil & $1 \cdot 5$ & 1.4 & $1 \cdot 7$ & $3 \cdot 0$ & $1 \cdot 2$ \\
\hline Water & $81 \cdot 8$ & $89 \cdot 1$ & 76.4 & $89 \cdot 3$ & $88 \cdot 2$ & 88.0 \\
\hline
\end{tabular}

${ }^{1}$ From a normal 1 year control.

were well preserved. Large numbers of phagocytic and transitional microglial cells containing sudanophil lipid were present in the central white matter but not in the central cores of the gyri.

Changes in the nerve cells The malformed areas of the cerebral cortex showed the usual changes of pachygyria. The depth of the grey matter was increased, there was no granular layer, and a broad, ill-defined zone of heterotopic islands of nerve cells lay beneath the more compact cortical layer of grey matter. No abnormally large nerve cells were seen. There was no evidence of a destructive process affecting nerve cells in any part of the brain except in the cerebellum where the granular layer was degenerated selectively. The greatest loss of granules was in the posterior part of the lateral lobes and vermis, but elsewhere this layer showed a diffuse reduction in cell density. The Purkinje cells, the basket and tangential fibres, and the dentate nuclei were intact (Fig. 9). The atrophied areas showed fibrillary gliosis of the gyral cores and proliferation of the Bergmann fibrils.

The leptomeninges, choroid plexus, and intracerebral vessels appeared normal.

CHEMISTRY The results of the analysis of the cerebral grey and white matter are given in the Table. The methods used are those cited in a previous paper (Norman, Oppenheimer, and Tingey, 1961). The brain had been in formalin for three months before analysis. The normal control of two and a half years had been fixed for four years. We have also included figures for the normal neonatal brain based on averages of several specimens fixed in formalin for about a year.

\section{DISCUSSION}

Signs of a progressive neurological illness had not been observed in this patient, probably because they had been masked by the severe cortical malformation. This latter finding is extremely rare in the leucodystrophies and the only comparable example we are aware of is the first of Seitelberger's (1954) cases of Pelizaeus-Merzbacher disease in which a patch of micropolygyria was found in the frontal cortex. The 'megalencephaly' often reported in other types of infantile leucodystrophy may be attributed to the inbibition of fluid by the degenerated white matter and not to pre-existing malformation. The combination of leucodystrophy and widespread pachygyria in our case is unique. In other recorded examples of this malformation, and in agyria, the white matter has usually been well myelinated, though its volume is reduced and the lateral ventricles enlarged. An exception is the case recorded by Kramer (1956) in which death had occurred at the age of 1 year. The myelination of the cerebral and cerebellar white matter was poor but considerably better than in the present case. Droplets of fat were present in the microglial cells and free in the tissues both in the white matter and in the cerebral cortex. In a personal communication Kramer says that the condition did not suggest a leucodystrophy, and it seems likely that anoxia during the terminal illness may have been responsible for the changes.

It is generally held that an important pathogenetic factor responsible for this disorder of development is a retardation in the migration of the neuroblasts from the ependymal matrix to the periphery of the hemisphere. Since the chances of two rare conditions occurring together in the same brain are very small, 
it may be suggested that both the malformative and degenerative processes are the expressions of a genetic influence manifesting itself at different stages of cerebral development. A similar hypothesis has been advanced to explain the occurrence of widespread neuronal degeneration in certain brains with cerebellar hypoplasia (Norman and Urich, 1958; Norman, 1961).

While it is not known whether the other sib in this family is suffering from a demyelinating condition, the extraordinarily close physical resemblance between the brother and sister leaves little doubt that the same type of cerebral malformation is common to both.

The diffuse distribution of the fat granule cells throughout much of the demyelinated or poorly myelinated regions in this brain suggests that the degeneration was of recent origin. On the other hand, there were areas of severe demyelination without fatty products, as in the inferior olives. The intensification of the gliosis in the latter situation may indicate that the lesions were older and had reached their final stage, though it is possible that an element of arrested myelination may have been present. As in other leucodystrophies and lipidoses of early life there are probably faults of anabolism as well as the more overt signs of myelin catabolism (Poser, 1961).

The selective degeneration of the granular layer of the cerebellum found in this brain has been reported in metachromatic leucodystrophy (Peiffer, 1959; Norman, Urich, and Tingey, 1960) and is a well known feature of the Batten type of amaurotic family idiocy.

The results of the chemical analysis of the white matter are also consistent with the findings in other leucodystrophies. The lipid hexosamine, and particularly its neuraminic acid component, were raised above normal levels for this age group. According to Edgar $(1957,1961 \mathrm{~b})$ an increased lipid hexosamine constantly distinguishes a leucodystrophy from Schilder's disease, and in our other cases of leucodystrophy, of the Krabbe, metachromatic and sudanophil types, the lipid hexosamine and the neuraminic acid levels have also shown significant elevations. In the present case hexosamine was also markedly increased in the grey matter, which in other respects did not show any significant chemical change. The residue hexosamine (a measure of polysaccharides) was also substantially increased both in the white and grey matter, but according to Edgar this may occur in demyelinating conditions other than leucodystrophy. The amount of the myelin-forming constituents, with the exception of sphingomyelin, was considerably reduced. We believe that this latter finding is correct since similar values for sphingomyelin have been obtained in duplicate estimations by difference in the choline fractions. The poor myelination in this case cannot, therefore, be attributed to a simple retardation in myelin formation, even though the levels of the other myelin-forming constituents closely approximated to the neonatal state. Edgar (1961a) has also found discrepancies between the degree of histological demyelination and the amounts of sphingomyelin in cases of sclerosing encephalitis of the van Bogaert type. It is of interest to note that the lipid sulphur was. reduced in this brain, as in a previously recorded case of Pelizaeus-Merzbacher disease (Norman and Tingey, 1961). In two other forms of sudanophil leucodystrophy which were reported in the same paper, sulphur was present in normal amount despite the severe demyelination. The abnormally high figure for cholesterol ester is not surprising in view of the large amount of doubly refractile lipid in the tissues.

Finally, the presence of foam cells in the alveoli of the lungs requires some comment. The histological appearances suggest that this is a lipoid pneumonia and the failure to reduce osmium tetroxide suggests the presence of a saturated fatty acid. It is doubtful, however, whether osmium tetroxide reduction is of much value in determining the nature of fats (Pearse, 1960). We have been able to exclude liquid paraffin and cod liver oil so that some food material seems the likely source. Nevertheless the fact that the child suffered from a sudanophil leucodystrophy naturally raises the question of whether the lung lesions were in some way related. In a true lipidosis, such as Niemann-Pick's disease or the visceral form of Tay-Sachs disease, histiocytes are present both in the lung alveoli and in the parenchyma (Norman, Urich, Tingey, and Goodbody, 1959). We therefore do not think that the alveolar foam cells in the present case can be plausibly related to the cerebral condition, but certainly the lungs of further cases should be carefully examined in an attempt to settle the point.

\section{SUMMARY}

The brain of a paraplegic, microcephalic idiot, aged 2 years 4 months at death, showed pachygyria and diffuse demyelination of the centrum ovale, cerebellar white matter, and parts of the brain-stem. The degenerated areas were crowded with microglial phagocytes containing sudanophil and doubly refractile lipids. Axis cylinders were well preserved. Nerve cells were unaffected except in the cerebellar cortex where there was a selective degeneration of the granular layer. This demyelinating condition has been classed as a sudanophil leucodystrophy. 
Chemical analysis of formalin-fixed material revealed a general reduction in the myelin-forming constituents with the exception of the sphingomyelin. Cholesterol esters were abnormally increased as were neuraminic acid, lipid hexosamine, and residue hexosamine. An elder sibling shows a closely similar clinical picture.

This work has been done with the help of the Nuffield Foundation.

\section{REFERENCES}

Edgar, G. W. F. (1957). In Cerebral Lipidoses, p. 48, ed. J. N. Cumings. Blackwell, Oxford.

_ (1961a). In Encephalitides, p. 648, ed. L. van Bogaert, J. Radermecker, J. Hozay, and A. Lowenthal. Elsevier, Amsterdam. (1961b). Neurochemistry Symposium. 7th International Congress of Neurology. Rome. (In the press.)

Einarson, L., and Strömgren, E. (1961). Acta Jutland, 33, 1.

Hallervorden, J. (1957). In Handbuch der speziellen pathologischen Anatomie und Histologie, Vol. 13, Pt. 1, p. 716, ed. O Lubarsch, F. Henke, and R. Rössle. Springer, Berlin.

Kramer, W. (1956). J. Neuropath. exp. Neurol., 15, 471.

Norman, R. M. (1961). Arch. Dis. Childh., 36, 96.

-, Oppenheimer, D. R., and Tingey, A. H. (1961). J. Neurol. Neurosurg. Psychiat., 24, 223.

- and Tingey, A. H. (1961). Neurochemistry Symposium. 7th International Congress of Neurology. Rome. (In the press.) , and Urich, H. (1958). Arch. Dis. Childh., 21, 159.

,-- , and Tingey, A. H. (1960). Brain, 83, 369.

$-\frac{1}{409},-$, and Goodbody, R. A. (1959). J. Path. Bact., 78,

Pearse, A. G. E. (1960). Histochemistry, Theoretical and Applied, 2nd ed., p. 310. Churchill, London.

Peiffer, J. (1959). Arch. Psychiat. Z. Neurol., 199, 417.

Poser, C. M. (1961). Arch. Neurol. (Chic.), 4, 323.

- and Bogaert, L. van (1956). Acta Psychiat. (Kbh.), 31, 285

Schilder, P. (1912). Z. Neurol. Psychiat., 10, 1.

Seitelberger, F. (1954). Wien. Z. Nervenheilk., 9, 228.

\section{The August 1962 Issue}

\section{THE AUGUST 1962 ISSUE CONTAINS THE FOLLOWING PAPERS:-}

Sources of error in the biochemical diagnosis of muscular dystrophy w. H. S. THOMSON

Observations on peripheral servo mechanisms in Parkinsonian rigidity WILLIAM WARD HOFMANN

The completion of visual forms across hemianopic field defects ELIZABETH K. WARRINGTON

Diffuse hypertrophy of the cerebellum THOMAS COOK, SHIRLEY HOLT, and P. O. YATES

Studies in the development and breakdown of the use of names GERARD ROCHFORD and MOYRA WILLIAMS

I The relationship between nominal dysphasia and the acquisition of vocabulary in childhood

II Experimental production of naming disorders in normal people

Toxic polyneuritis in Bombay due to orthocresylphosphate poisoning D. D. VORA, DARAB K. DASTUR, BEATRIZ M. BRAGANCA, L. M. PARIHAR, C. G. S. IYER, R. B. FONDEKAR, and K. PRABHAKARAN
Mental disturbances after thalamolysis E. S. WATKINS and D. R. OPPENHEIMER

Some observations on memory impairment after temporal lobectomy for epilepsy EUSTACE A. SERAFETINIDES and MURRAY A. FALCONER

Changes in tactile discrimination and in visual reaching after successive and simultaneous bilateral posterior parietal ablations in the monkey G. ETTLINGER and J. E. KALSBECK

Perephlebitis retinae and multiple sclerosis E. J. FIELD and J. B. FOSTER

Myoclonic encephalopathy of infants M. KINSBOURNE

The relation between complaints of persistent pain and family size THOMAS A. GONDA

Report by the Commission of Neuroradiology (World Federation of Neurology)

Book reviews

Copies are still available and may be obtained from the PUBLISHING MANAGER, BRITISH MEDICAL ASSOCIATION, TAVISTOCK SQUARE, W.C.I, price 17s. 6D. 